\title{
Computing the Absorption and Emission Spectra of
}

\section{MethylCytidine in Different Solvents: a Test-Case for Different Solvation Models.}

\author{
L. Martínez-Fernández ${ }^{a}$, A. J. Pepino, ${ }^{b}$ J. Segarra-Martí, ${ }^{b, c}$ A. Banyasz, ${ }^{d^{*}}$ M. Garavelli, ${ }^{b, c}{ }^{*} R$. \\ Improta $^{a^{*}}$
}

a. Istituto di Biostrutture e Bioimmagini CNR, Via Mezzocannone 16, I-80134 Napoli, Italy.

b. Dipartimento di Chimica “G. Ciamician”, Università di Bologna, Bologna, Italy.

c. École Normale Supérieure de Lyon, CNRS, UMR 5182, Université de Lyon, 46 Allée d'Italie, F-69364 Lyon Cedex 07, France.

d. LIDYL, CEA, CNRS, Université Paris-Saclay, F-91191 Gif-sur-Yvette, France.

e-mail: akos.banyasz@cea.fr,marco.garavelli@unibo.it,robimp@unina.it

KEYWORDS (Word Style "BG_Keywords"). DNA, Solvent Effects, optical spectra, Molecular Dynamics, TD-DFT, QM/MM

ABSTRACT (Word Style "BD_Abstract”).

The optical spectra of 5-methylcytidine in three different solvents (tetrahydrofuran, acetonitrile and water) is measured, showing that both the absorption and the emission maximum in water 
are significantly blue-shifted $(0.08 \mathrm{eV})$. The absorption spectra are simulated based on CAMB3LYP/TD-DFT calculations, but including solvent effects with three different approaches; (i) a hybrid implicit/explicit full Quantum Mechanical approach, ii) a mixed QM/MM static approach; iii) a $\mathrm{QM} / \mathrm{MM}$ method exploiting the structures issuing from Molecular Dynamics classical simulations. Ab-Initio Molecular dynamics simulations based on CAM-B3LYP functionals have also been performed. The adopted approaches all reproduce the main features of the experimental spectra, giving insights on the chemical-physical effects responsible of the solvent shifts in the spectra of 5-methylcytidine and providing the basis for discussing advantages and limitations of the adopted solvation models. 


\section{INTRODUCTION.}

The biological relevance of the interaction between DNA and ultraviolet radiation, a process that can lead to pernicious consequences for living organisms, gives account of the many experimental and theoretical works studying the optical spectra of nucleobases, which are responsible for the spectroscopic properties of DNA in UVC-UVA range. ${ }^{1-8}$ Though most of the computational contributions tackled the gas phase properties, there are several studies also in the condensed phase -essentially in water- and for most of the nucleobases there is nowadays a fairly good understanding of solvent effect on the lowest energy excited electronic states, e.g. their energy ordering in the Franck-Condon (FC) region, their fluorescence minima and so on. ${ }^{2,6}$ In this respect, cytosine ${ }^{9,10}$ and, even more, its derivative 5-methylcytosine have been investigated less-thoroughly in the condensed phase. 5-methylation of cytosine is the most common epigenetic modification in the DNA, extensively highlighted in molecular biology. ${ }^{11-15}$ This modified nucleobase is frequently present in mutational hotspots, i.e. DNA-sequences more prone to spontaneous mutation than expected from a random distribution. ${ }^{16}$ Although 5methylcytosine replaces only $\sim 1-5 \%$ of cytosine (C) DNA residues, ${ }^{17}$ it was found to be correlated with $\sim 30 \%$ of points mutations. ${ }^{16,18,19}$ Besides the possible role of deamination processes, ${ }^{15,}{ }^{20}$ hotspots containing 5-methylcytosine are up to 5 to 15 -fold more sensitive to pyrimidine photodimerization upon ultraviolet irradiation compared to $\mathrm{C}^{21-23}$ The steady-state and Time-resolved (TR) spectroscopic properties of 5-methylcytosine have been tackled by several studies. ${ }^{24-27}$ From a theoretical point of view, other $\mathrm{C}$ derivatives have received more attention $^{27-34}$ and the works on 5-methylcytosine are instead scarce and limited to the gas phase. ${ }^{31,}$ ${ }^{35,36}$ Eventually, it is also apparent that interaction with the environment (including the solvent as well as the sugar moiety) is mandatory to appreciate and understand all the effects recorded in vivo.

As a first step of a general assessment of the excited state dynamics of $\mathrm{C}$ derivatives in solution, here we report a study of the absorption and (for the first time) emission spectra of 5methylCytidine $(5 \mathrm{mCd})$ in different solvents, namely tetrahydrofurane (THF), acetonitrile $(\mathrm{ACN})$, and water (WAT). The experimental spectra are compared with those obtained by using three different methodological approaches (see next section), always exploiting Time-Dependent (TD)DFT and CAM-B3LYP functional for the QM part; i) a static full QM method, based on QM geometry optimizations of $5 \mathrm{mCd}$ (or of a cluster including a small number of water 
molecules) and considering bulk solvent effect by a continuum solvation model as the Polarizable Continuum Model (PCM), ii) a static QM/MM method, based on QM/MM geometry optimizations and where solvent effect is treated at the MM level and iii) a dynamical QM/MM method, where Molecular Dynamics (MD) simulations provide the structures to be used in QM/MM single point calculations. A critical comparison among the predictions of all these approaches is the second, important, goal of the present study.

Properly considering solvent effect in photo-activated processes is extremely important since it can govern the interplay between the different excited states and modulate the shape of their Potential Energy Surface (PES), including the energy barrier for non-radiative ground state recovery. ${ }^{9}, 10,37,38$ Due to the capability of the solvent to alter the chemical behavior of molecules, ${ }^{39}$ the study of solvent effects has gained attention already several decades ago ${ }^{40}$ and within many research areas (proteins ${ }^{41}$, molecular recognition $^{42}$, nanotechnology ${ }^{43} \ldots$ ); nonetheless understanding the molecular basis for solvent effects can be still considered a challenging problem for chemical research. ${ }^{44}$ For what concerns inclusion of solvation in computational methods $^{2,45}$ several different methods has been proposed until now. Among the most commonly used approaches, we can distinguish implicit/continuum ${ }^{46-50}$ as the $\mathrm{PCM}^{48,49}$ and explicit models $\mathrm{s}^{51,52}$, often exploiting MD simulation to obtain a proper averaging of the position of solvent molecules. ${ }^{53,}{ }^{54}$ Combinations between these approaches, as the mixed discrete/continuum approaches have also been applied, providing a fairly accurate description of solvent-solute interactions, ${ }^{2,9}$ and have been also successfully applied to nucleobases. ${ }^{2,55-57}$ On the other hand, it is clear that each approach has its own advantages and limitations, and that synoptical studies can provide useful insights. The number of detailed studies comparing these methods are limited and most of them focused on water, ${ }^{9,58}$ whereas the organic solvents have received much less attention..$^{59,60}$ Thereby, besides the intrinsic biochemical relevance of $5 \mathrm{mCd}$ (including the effect of the sugar ring), our study is of methodological interest, since it is one of the first documenting THF and ACN solvation boxes in MD simulations.

\section{Methods}

\subsection{The simulation of the absorption and the emission spectrum}

From a computational point of view, three different approaches have been used to model how the absorption spectrum of $5 \mathrm{mCd}$ (5-methylcytidine was considered throughout this study, Figure 1) changes in different solvents. 
A) Static QM/PCM approach. We first optimized the ground state geometry of $5 \mathrm{mCd}$, using the PCM/CAM-B3LYP/6-31G(d) level of theory. Considering the relative orientation of the sugar and the purine rings, two main different conformers are possible, syn and anti (see Figure S3). According to our MD simulations both conformers are present in solution at room temperature, thus contributing to the optical spectra. In order to get a more meaningful comparison between the results of the different approaches, we have therefore optimized and computed the spectra for both conformers. As discussed in the SI, in general, our conclusions do not qualitatively depend on the choice of the conformer. For a sake of concision, in the main text we shall mainly discuss the results concerning the anti conformer. The vertical absorption energies (VAE) for the first 10 excited states have been computed at the PCM/TD-CAMB3LYP/6-31G(d) level. Only bulk solvent effects have been included for THF and ACN, whereas for WAT we resorted to a mixed procedure explicitly considering four water molecules of the first solvation shell, WAT $+4 \cdot \mathrm{H}_{2} \mathrm{O}$ (see Figure 1a for the specific position on the water molecules), which will be our reference model for water. According to our previous experience, inclusion of explicit $\mathrm{H}_{2} \mathrm{O}$ molecules into the first solvation shell is indeed important to accurately account for its hydrogen bonding activity and its effects on the different electronic excited states. ${ }^{55,61}$ This procedure provides the VAE (the so called 'stick spectra'), while vibrationally resolved spectra, can be obtained by using the effective time independent (TI) and TD approaches described in detail (FCclasses) ${ }^{62}$, based on Hessian computations for the different states of interest. On the other hand, our previous study on $\mathrm{C}^{63}$ shows that the computed absorption spectrum is broad $(\sim 0.7 \mathrm{eV})$ and featureless already in the gas phase and at $0 \mathrm{~K}$. As a consequence, in this paper, for a sake of simplicity and in order to avoid the possible artifact due to the choice of the computational model for the solvent, ${ }^{64}$ we avoid the explicit computation of vibrationally resolved spectra and we simply apply a phenomenological broadening $(0.35 \mathrm{eV})$ to each VAE, which reproduce the width of the lowest energy absorption band in the gas phase and enables an easier and direct comparison with experiments. Please note that this value, which does not include solvent inhomogeneous broadening ${ }^{65}$ or the effect of temperature, has to be considered a lower estimate compared to the experimental one. Furthermore, inclusion of vibronic effects does not simply induce a broadening of the spectrum but also a shift of the maxima. ${ }^{66}$ Analytical expressions for the first-moment M1 of the normalized absorption line 
shows that, since the excited state frequencies are lower than the ground state one, we can expect a systematic red-shift of the computed absorption maximum with respect to the Vertical Excitation Energy; vibrationally resolved calculations on several representative molecules provide red-shifts of $0.1 \sim 0.3 \mathrm{eV} .{ }^{66}$ For what concerns cytosine derivatives, the maximum of the computed vibrationally resolved spectrum of the keto-amino tautomer of Cyt in the gas phase at room temperature is indeed shifted by $-0.2 \mathrm{eV}$ with respect to the Vertical Excitation Energy. ${ }^{63}$ Such a red-shift is missing in the spectra computed here. ${ }^{66}$

B) Static QM/MM approach. A similar procedure to the one described in A) was followed in this case, but using an explicit solvation model, i.e. considering movable solvent MM molecules within a radius of $5.5 \AA$ respect to any QM atom included in our model, while leaving the rest of the solvent box frozen along the optimization procedure. Test calculations in water starting geometry optimizations from a different cluster do not provide significantly different absorption and emission energies (see ESI). After ground state geometry optimizations (for both syn and anti conformers) at the CAM-B3LYP/6-31G(d)/MM level, we have calculated the VAE for the first 10 excited states at the TD-CAM-B3LYP/6-31G(d)/MM level. Also in this case the same phenomenological broadening $(0.35 \mathrm{eV})$ was applied to each VAE to simulate the absorption spectrum.

C) Dynamic QM/MM MD approach. First, we have run MD simulations of 5mCd in WAT, ACN and THF for $100 \mathrm{~ns}$ using Amber force fields (see section 2.2). Then, a total of 200 snapshots were extracted from these dynamics (one snapshot every $500 \mathrm{ps}$ ). This approach delivers most of the snapshots presenting syn conformation (since it is the predominant conformer along the MD, see Figure S3) but also some anti and intermediate snapshots are present. TD-CAM-B3LYP/631G(d)/MM single point calculations were performed on top of each snapshot to compute the VAE. To this aim, the COBRAMM package ${ }^{67}$ was used and different layers were defined into our calculations, see Figure 1b. The high layer (HL) includes the whole $5 \mathrm{mCd}$ molecule, the medium layer (ML) contains all the WAT/ACN/THF molecules within a radius of $5.5 \AA$ respect to any HL atom and the low layer contains the rest of the solvent bulk. In order to get some insights on the dependence of the spectra computed by model $\mathrm{C}$ on the use of MM geometries for $5 \mathrm{mCd}$, we have also run $\mathrm{MD}$ simulations freezing the geometry of $5 \mathrm{mCd}$ at the structure provided by PCM/CAM-B3LYP/6-31G(d) geometry optimizations, and then computed the spectra (see Figure S7 of the ESI) by using the same procedure just described (model C'). 
For what concerns the emission spectra in solution, we have limited our study to the static approaches, (A) QM/PCM and (B) QM/MM, proceeding as described above for the absorption process, but optimizing the first excited state $\left(\mathrm{S}_{1}\left(\pi \pi_{1}{ }^{*}\right)\right)$ either at the QM/PCM and QM/MM levels (QM:TD-CAMB3LYP/6-31G(d)), (see Figure S1).

\subsection{Computational Details.}

QM Calculations: The ground and excited state minima of $5 \mathrm{mCd}$ were optimized by means of time-dependent density functional theory (TD-DFT), using the CAM-B3LYP ${ }^{68}$ functional combined with the $6-31 \mathrm{G}(\mathrm{d})^{69}$ basis set. The absorption spectra at the ground state optimized geometry were simulated using the same functional and basis set, however the effect of increasing (up to $6-311+\mathrm{G}(2 \mathrm{~d}, 2 \mathrm{p})$ ) the basis set has been tested. To model the solvent bulk effects (THF, ACN and WAT) a polarizable continuum model (PCM) ${ }^{49,70}$ was used.

AIMD calculations: Ab Initio Molecular Dynamics (AIMD) were run using the using the Atom Centered Density Matrix Propagation ${ }^{71}$ molecular dynamics model as implemented in Gaussian09. Due to the large computational cost of this simulations we have used CAM-B3LYP combined in this case with a smaller basis set 6-31G. All QM calculations were performed with Gaussian09 program. ${ }^{72}$

MD simulations: Molecular dynamics simulations were carried out employing the f99 force field as implemented in the AMBER 11 package. ${ }^{73}$ The different systems under study contained the nucleoside moieties (described by non-standard residues generated with Antechamber) surrounded by cubic solvent boxes of $12 \AA$, employing TIP3P ${ }^{74}$ for explicit water molecules and the gaff force field for ACN and THF. ${ }^{75}$ The entire systems were heated from 0 to $300 \mathrm{~K}$ for $1 \mathrm{~ns}$ at constant volume and pressure (1 atm), and then a production run was performed for $100 \mathrm{~ns}$ recording the snapshots every 200 fs. Cluster analysis based on a Root Mean Square (RMS) coordinate deviation analysis was performed over all recorded snapshots employing a $2.0 \AA$ difference as implemented in the MMTSB toolbox (see Figure S3). Similarly to what has been previously done for similar systems, ${ }^{76}$ one main cluster was located and the snapshot with the closest geometrical parameters to the centroid of the average of the structure was selected (syn conformer, see SI for further details). 

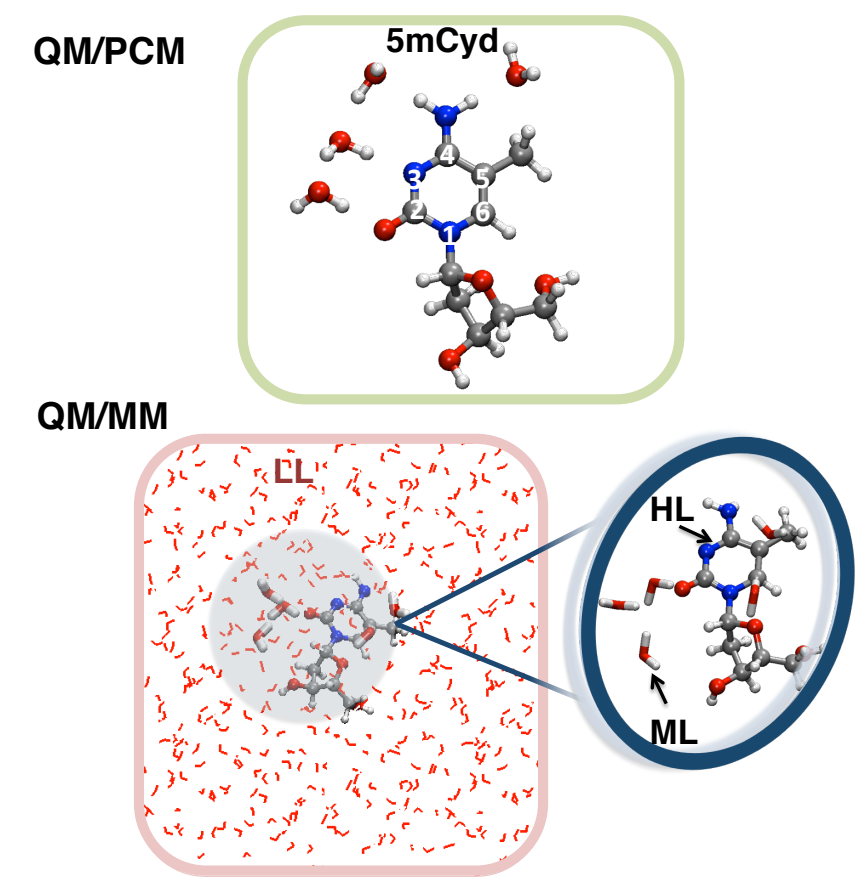

Figure 1. Representative schemes for 5-methylcytidine (5mCd) molecule used in a) QM WAT+4・H QM/MM calculations: low layer (LL) water molecules in sticks, medium layer (ML) water molecules in tubes and high layer (HL) 5-methylcytidine in ball\&sticks. See a) for 5-methylcytidine atoms labeling.

QM/MM Calculations: The COBRAMM interface ${ }^{67}$ was employed to connect the QM $(\text { Gaussian09) })^{72}$ and MM (Amber) ${ }^{73,77}$ regions employing an electrostatic embedding approach. ${ }^{78}$ To this end, three different layers were defined: a high layer containing the QM region $(5 \mathrm{mCd})$, a medium layer enclosing all movable solvent molecules within a $5.5 \AA$ radius, and a low layer that contains the rest of the MM atoms that remain frozen during the simulations. QM/MM optimizations were carried out employing Gaussian $09^{72}$ package.

\subsection{Experiments}

Materials. The 5-methylcytidine (purity: >99\%) was obtained from Fluorochem and it was used as received. Acetonitrile (ACN) and tetrahydrofuran (THF) were obtained from Merck (UVAsol grade) and were used without further purification. Aqueous solutions were prepared using Millipore water (Milli-Q Synthesis).

Steady-state spectroscopic measurements. Absorption and fluorescence spectra were recorded with a Perkin Lamda 850 spectrophotometer and a Fluorolog-3 (Horiba, Jobin-Yvon) fluorimeter, respectively using $1 \times 1 \mathrm{~cm}$ quartz cells $(\mathrm{QZS})$. For the fluorescence measurements 
the excitation source was a $450 \mathrm{~W}$ Xe-arc lamp. The emission was detected at right-angle configuration, the recorded spectra were corrected for the response of the detection system. Due to the low fluorescence quantum yield of 5-methylcytidine, the emission of the solvents was not negligible compared to the fluorescence intensity. Therefore, their contributions were subtracted from the fluorescence spectra. For the fluorescence quantum yield measurements thymidine monophosphate (TMP) was used as a reference $\left(\phi_{\text {fluo }}=1.54 \times 10^{-4}\right)^{79}$ instead of the widely used quinine sulfate dihydrate solution, ${ }^{80}$ because of its more similar fluorescence quantum yields and spectra.

\section{RESUlts.}

\subsection{Absorption Spectra.}

Figure 2 shows the experimental and calculated spectra obtained with the three procedures described above. The experimental absorption spectrum of $5 \mathrm{mCd}$ in water (black line, Figure 2) presents three main bands, placed at $278 \mathrm{~nm}$ (hereafter labeled as band I), $242 \mathrm{~nm}$ (band II) and a high-energy band below $200 \mathrm{~nm}$ (band III). Band II is the less intense one (ca. 80\% of band I), whereas band III is significantly more intense than the other two. The maximum of the lowest absorption band of $\mathrm{C}$ in water falls at $\sim 270 \mathrm{~nm}$, indicating that methyl substitution leads to a red shift of $\sim 8 \mathrm{~nm}$ of the lowest energy bright transition (see the section 'Discussion' below).

A) Static QM/PCM. The WAT $+4 \bullet \mathrm{H}_{2} \mathrm{O}$ absorption spectrum is depicted in Figure 2a in black. This calculation indicates that three main bright $\pi \pi^{*}$ transitions $\left(S_{1}\left(\pi \pi_{1}{ }^{*}\right), S_{4}\left(\pi \pi_{2}{ }^{*}\right), S_{6}\left(\pi \pi_{3}{ }^{*}\right)\right)$ are responsible for the three main peaks at $241 \mathrm{~nm}(5.13 \mathrm{eV}), 205 \mathrm{~nm}(6.03 \mathrm{eV})$ and $189 \mathrm{~nm}(6.54$ $\mathrm{eV}$ ), reproducing the relative intensity of the bands I, II, and III in the experimental spectrum, but for a small overestimation of band II intensity ( $\sim 98 \%$ of band I). Figure 3 reports the molecular orbitals more involved in these transitions. From a quantitative point of view, the computed spectra are uniformly blue-shifted by $\sim 0.6 \mathrm{eV}$ with respect to the experimental one. However,

this discrepancy is reduced by increasing the basis set to $6-311+\mathrm{g}(2 \mathrm{~d}, 2 \mathrm{p})(251 \mathrm{~nm}(4.93 \mathrm{eV}))$, leading to a residual difference $\sim 0.4 \mathrm{eV}$, which is mainly due to the lack of vibronic and temperature effects, as compared to the spectra computed in the gas phase. ${ }^{66}$ At difference with the experiments, static QM/PCM approach does not predict any absorption between band I and II. 
B) Static QM/MM (Figure 2b, black line). This method predicts the absorption maximum for band I at $244 \mathrm{~nm}(5.08 \mathrm{eV})$ slightly improving the value recovered in A. However, in this case band II is blue shifted towards $196 \mathrm{~nm}(6.31 \mathrm{eV})$ overlapping with band III $(184 \mathrm{~nm}, 6.72 \mathrm{eV})$, leading to band-shapes in qualitative disagreement with the experiment.

C) Dynamic QM/MM MD According to this procedure (black line in Figure 2c), the absorption maximum for band I is placed at $268 \mathrm{~nm}$ in WAT, while bands II and III lie at 220 and $190 \mathrm{~nm}$. The computed absorption maxima are thus in agreement with the experimental evidence, notwithstanding also this approach relies on CAM-B3LYP/6-31G(d) calculations for the QM part (see the Discussion below). The intensities are also fairly well reproduced, except for a small underestimation of the predicted intensity of band II ( $\sim 60 \%$ of band I). Interestingly, this approach predicts some absorption at $\sim 270 \mathrm{~nm}$, i.e. between band I and II, reducing the discrepancy with respect to the experiments.

Assigning the contributing state to each band in this dynamic approach is more complicated but the decomposition of the spectrum (Figure S5) shows that $S_{1}\left(\pi \pi_{1}^{*}\right)$ state is responsible for band I. However, also a small fraction of $\mathrm{S}_{2}$ falls in the energy range of band $\mathrm{I}$, corresponding to specific snapshots where the $S_{2}\left(n \pi^{*}\right)$ excited state is significantly mixed with the $S_{1}\left(\pi \pi_{1}^{*}\right)$ increasing its oscillator strength or it is so stabilized that becomes the lowest energy adiabatic state (this features appears for C5-C6 bond distances shorter than the average value). On the other hand, the absorption observed at $\sim 270 \mathrm{~nm}$ arises from snapshots where the $\mathrm{S}_{2}\left(\mathrm{n} \pi^{*}\right)$ state increases its oscillator strength due to mixing with the $\left(\pi \pi_{2}{ }^{*}\right)$ state. The $\pi \pi_{2}{ }^{*}$ is the state mainly responsible for band II but for a significant number of snapshots it is strongly coupled to the $\mathrm{n}_{\mathrm{O}} \pi^{*}$ state (increasing the latter its oscillator strength). Many adiabatic states contribute to band III.

\section{Absorption Solvent Shifts}

Changing the solvent from WAT to ACN affects to a different extent the three main bands of the experimental spectrum (Figure 2). Whereas the experimental maximum of band I is significantly red shifted (from 278 in WAT to $283 \mathrm{~nm}$ in ACN, $\Delta_{\text {WAT } \rightarrow \text { ACN }} 5 \mathrm{~nm} /-0.08 \mathrm{eV}$ ), bands II and III do not significantly change in energy, but their intensity increases. The spectra in ACN and THF are extremely similar; the shift of band I has a very small red-shift in $\operatorname{THF}\left(\Delta_{\mathrm{ACN} \rightarrow \mathrm{THF}} 1 \mathrm{~nm} /-0.01 \mathrm{eV}\right)$ 
while the intensity of band III slightly increases. The spectra computed in ACN and THF are also shown in Figure 2.

A) Static QM/PCM The spectrum in ACN exhibits bands at $248\left(\mathrm{~S}_{1}\left(\pi \pi_{1}{ }^{*}\right), 5.00 \mathrm{eV}\right), 202$ $\left(\mathrm{S}_{4}\left(\pi \pi_{2}\right), 6.14 \mathrm{eV}\right)$ and $185 \mathrm{~nm}\left(\mathrm{~S}_{6}\left(\pi \pi_{3}{ }^{*}\right), 6.68 \mathrm{eV}\right)$ (Figure 2a). Band I is thus red-shifted with respect to WAT $\left(\Delta_{\text {WAT } \rightarrow \text { ACN }} 7 \mathrm{~nm} /-0.13 \mathrm{eV}\right.$, Table 1$)$, in agreement with the experiment. The relative intensity of band II and III increases with respect to WAT, band II becoming more intense than band I in ACN. Decreasing the polarity from ACN to THF does not significantly change the position of band I $\left(\Delta_{\mathrm{ACN}_{\rightarrow} \mathrm{THF}} 1 \mathrm{~nm} /-0.03 \mathrm{eV}\right)$ and slightly increases the intensity of band III, as found in the experiment.

B) Static QM/MM In ACN band I falls at $259 \mathrm{~nm}(4.77 \mathrm{eV})$, band II $212 \mathrm{~nm}(5.82 \mathrm{eV})$ and band III at $188 \mathrm{~nm}(6.60 \mathrm{eV})$, with associated THF estimates of $258 \mathrm{~nm}(4.80 \mathrm{eV}), 205 \mathrm{~nm}(6.04 \mathrm{eV})$ and $185 \mathrm{~nm}(6.70 \mathrm{eV})$, respectively. The computed solvent shift for band I is thus larger than the experimental one $\left(\Delta_{\mathrm{WAT} \rightarrow \mathrm{ACN}} 15 \mathrm{~nm} /-0.31 \mathrm{eV}\right)$ while $\Delta_{\mathrm{ACN} \rightarrow \mathrm{THF}}-1 \mathrm{~nm} / 0.03 \mathrm{eV}$ is consistent with the experimental estimates. $\Delta_{\mathrm{WAT}_{\rightarrow} \mathrm{ACN}}$ shift is also larger than that estimated by the QM/PCM approach described above. This result can be explained by a different estimate of solvent effect on the $\mathrm{S}_{0}$ geometries by these two computational approaches. As in case A), the intensities for the middle energy band for THF is slightly overestimated with respect to the experiments, being this overestimation huge in case of the ACN spectrum, which could be ascribed to a more mixed character of the $\left(\pi \pi_{2}{ }^{*}\right)$ excitation in the latter. The solvent shift predicted for syn conformer (see $\mathrm{SI})$ is closer to the experimental one, $(-0.08 \mathrm{eV})$ suggesting a predominance of this conformer in non-hydrogen bonding solvents.

C) QM/MM MD As shown in Figure 2c, in ACN the maxima of the three main absorption bands fall at $275(4.51 \mathrm{eV}), 219(5.65 \mathrm{eV})$ and $193 \mathrm{~nm}(6.41 \mathrm{eV})$. These values are very similar in THF, except for band II that is blue-shifted; band I falls at $276 \mathrm{~nm}$, band II at $207 \mathrm{~nm}$, and band III at $191 \mathrm{~nm}$. As a consequence, the calculated QM/MM MD shifts for band I are $\Delta_{\text {WAT } \rightarrow \text { ACN }} 7 \mathrm{~nm} /-$ $0.11 \mathrm{eV}$ and $\Delta_{\mathrm{ACN} \rightarrow \mathrm{THF}} 1 \mathrm{~nm} /-0.01 \mathrm{eV}$, (see Table 1) in agreement with the experiment. However, although the intensity of band II is larger in ACN/THF with respect to WAT following the experimental trend, the relative intensity of this band is significantly underestimated by this computational approach. 


\section{Solvent effect on the lowest energy dark states}

Besides changing the position of band I, assigned to the $\left(\pi \pi_{1}{ }^{*}\right)$ state, solvation also affects the energy of the dark $\left(n_{N} \pi^{*}\right)$ and $\left(n_{O} \pi^{*}\right)$ states (see Table 2). These states, whose VAE is 5.92 and $6.46 \mathrm{eV}$ in WAT, respectively, are strongly stabilized in ACN and THF, following the same trend previously described for bright $\left(\pi \pi_{1}^{*}\right)$ state. However, the solvent $\Delta_{\text {WAT } \rightarrow \text { ACN }}$ shift associated to these dark states is much larger, reaching $\sim 0.3 \mathrm{eV}$ in case of the $\left(\mathrm{n}_{\mathrm{N}} \pi^{*}\right)$ state. In the QM/MM static case the predicted solvent shift for this $\left(\mathrm{n}_{\mathrm{N}} \pi^{*}\right)$ dark state is also larger $(\sim 0.7 \mathrm{eV})$ than the one found for the bright states $(0.3 \mathrm{eV})$. The other dark state $\left(\mathrm{n}_{\mathrm{O}} \pi^{*}\right)$ is also significantly destabilized in water, getting closer in energy and significantly mixing with the $\left(\pi \pi_{2}{ }^{*}\right)$ state (as shown by its larger oscillator strength and excited state density difference, see SI for further details). On the balance, going from an apolar solvent to water leads to a strong destabilization of the $n \pi^{*}$ excited states and to an increase of their intensity, due to the mixing with $\pi \pi_{2}$. This picture is very similar to that provided by a very recent study of the absorption spectrum of $\mathrm{C}$ in water by using QM/MM calculations. ${ }^{81}$ The destabilization of the dark $n \pi^{*}$ states in a hydrogen bonding (HB) solvent as WAT can be explained by the weakening of the hydrogen bond interaction due to the transfer of an electron of the LP of the Oxygen or the Nitrogen atoms (acting as strong HB acceptor) to the $\pi^{*}$ LUMO delocalized over the ring. 
Table 1. A) Calculated absorption energies [and oscillator strengths] for the bright state $\left(\pi \pi_{1}{ }^{*}\right)$, experimental absorption maxima for Band $\mathrm{I}$ in $\mathrm{eV}(\mathrm{nm})$ and the correspondent solvent shifts (in eV) in THF, ACN and WAT solutions. B) Calculated emission in $\mathrm{eV}(\mathrm{nm})$ and adiabatic energies in $\mathrm{eV}$ [oscillator strengths] for the optimized minima (planar $\left({ }^{\mathrm{pla}}\right)$ ); experimental fluorescence energies after $267 \mathrm{~nm}$ excitation together with the correspondent shifts in THF, ACN and WAT solutions.

\begin{tabular}{|c|c|c|c|c|c|}
\hline \multirow[t]{2}{*}{$\mathbf{A}$} & \multicolumn{3}{|c|}{ Band I absorption maxima $\left(\lambda_{\max }\right), \mathrm{eV}(\mathrm{nm})$} & \multicolumn{2}{|c|}{ Solvent Shifts $(\Delta), \mathrm{eV}$} \\
\hline & THF & $\mathrm{ACN}$ & WAT & $\Delta_{\mathrm{WAT}_{\rightarrow} \mathrm{ACN}}$ & $\Delta_{\mathrm{ACN}_{\rightarrow} \mathrm{THF}}$ \\
\hline & & & & \multicolumn{2}{|c|}{ ABSORPTION } \\
\hline $\mathrm{QM} / \mathrm{PCM}$ & $\begin{array}{c}4.97(249) \\
{[0.18]}\end{array}$ & $\begin{array}{c}5.00(248) \\
{[0.18]}\end{array}$ & $\begin{array}{c}5.13(241) \\
{[0.25]}\end{array}$ & -0.13 & -0.03 \\
\hline $\mathrm{QM} / \mathrm{MM}$ & $\begin{array}{c}4.80(258) \\
{[0.12]}\end{array}$ & $\begin{array}{c}4.77(259) \\
{[0.10]}\end{array}$ & $\begin{array}{c}5.08(244) \\
{[0.16]}\end{array}$ & -0.31 & 0.03 \\
\hline QM/MM MD & $4.50(276)$ & $4.51(275)$ & $4.62(268)$ & -0.11 & -0.01 \\
\hline EXP & $4.37(284)$ & $4.38(283)$ & $4.46(278)$ & -0.08 & -0.01 \\
\hline $\mathbf{B}$ & \multicolumn{3}{|c|}{ Emission maxima $\left(\lambda_{\max }\right), \mathrm{eV}(\mathrm{nm})$} & \multicolumn{2}{|c|}{ EMISSION } \\
\hline $\mathrm{QM} / \mathrm{PCM}$ & $\begin{array}{l}4.21(294) \\
4.58[0.16]\end{array}$ & $\begin{array}{l}4.26(291) \\
4.61[0.17]\end{array}$ & $\begin{array}{l}4.39(282) \\
4.78[0.25]\end{array}$ & -0.13 & -0.05 \\
\hline $\mathrm{QM} / \mathrm{MM}$ & $\begin{array}{l}3.94(315) \\
4.39[0.09]\end{array}$ & $\begin{array}{l}3.75(335) \\
4.44[0.05]\end{array}$ & $\begin{array}{l}4.39(282) \\
4.54[0.15]\end{array}$ & -0.64 & 0.19 \\
\hline EXP & $3.54(351)$ & $3.53(352)$ & $3.60(344)$ & -0.08 & 0.01 \\
\hline
\end{tabular}

Table 2. Static (QM/PCM and QM/MM) absorption energies for the dark states $\left(\mathrm{n}_{\mathrm{N}} \pi^{*}\right.$ and $\left.\mathrm{n}_{\mathrm{O}} \pi^{*}\right)$ in $\mathrm{eV}$ (nm) and oscillator strengths in brackets at the optimized ground state minimum. ${ }^{\text {(a) }}$ In these cases the $\mathrm{n}_{\mathrm{O}} \pi^{*}$ state is strongly mixed with the $\pi \pi_{2}^{*}$ state.

\begin{tabular}{|c|c|c|c|}
\hline & THF & ACN & $\mathrm{WAT}+4 \cdot \mathrm{H}_{2} \mathrm{O}$ \\
\hline \multicolumn{4}{|l|}{ QM } \\
\hline $\mathrm{n}_{\mathrm{N}} \pi^{*}$ & $\begin{array}{c}5.56(223) \\
{[0.00]}\end{array}$ & $\begin{array}{c}5.61(221) \\
{[0.00]}\end{array}$ & $\begin{array}{c}5.92(209) \\
{[0.06]}\end{array}$ \\
\hline $\mathrm{n}_{\mathrm{O}} \pi^{*}$ & $\begin{array}{c}\text { (a) } 5.98(207) \\
{[0.07]}\end{array}$ & $\begin{array}{c}\text { (a) } 6.01(206) \\
{[0.11]}\end{array}$ & $\begin{array}{c}\text { (a) } 6.46(191) \\
{[0.11]}\end{array}$ \\
\hline $\mathrm{QM} / \mathrm{MM}$ & THF & $\mathrm{CAN}$ & WAT \\
\hline $\mathrm{n}_{\mathrm{N}} \pi^{*}$ & $\begin{array}{c}5.18(239) \\
{[0.00]}\end{array}$ & $\begin{array}{c}5.11(242) \\
{[0.01]}\end{array}$ & $\begin{array}{c}5.87(211) \\
{[0.00]}\end{array}$ \\
\hline $\mathrm{n}_{\mathrm{O}} \pi^{*}$ & $\begin{array}{c}5.58(218) \\
{[0.00]}\end{array}$ & $\begin{array}{c}\text { (a) } 5.60(221) \\
{[0.01]}\end{array}$ & $\begin{array}{c}\text { (a) } 6.24(198) \\
{[0.07]}\end{array}$ \\
\hline
\end{tabular}




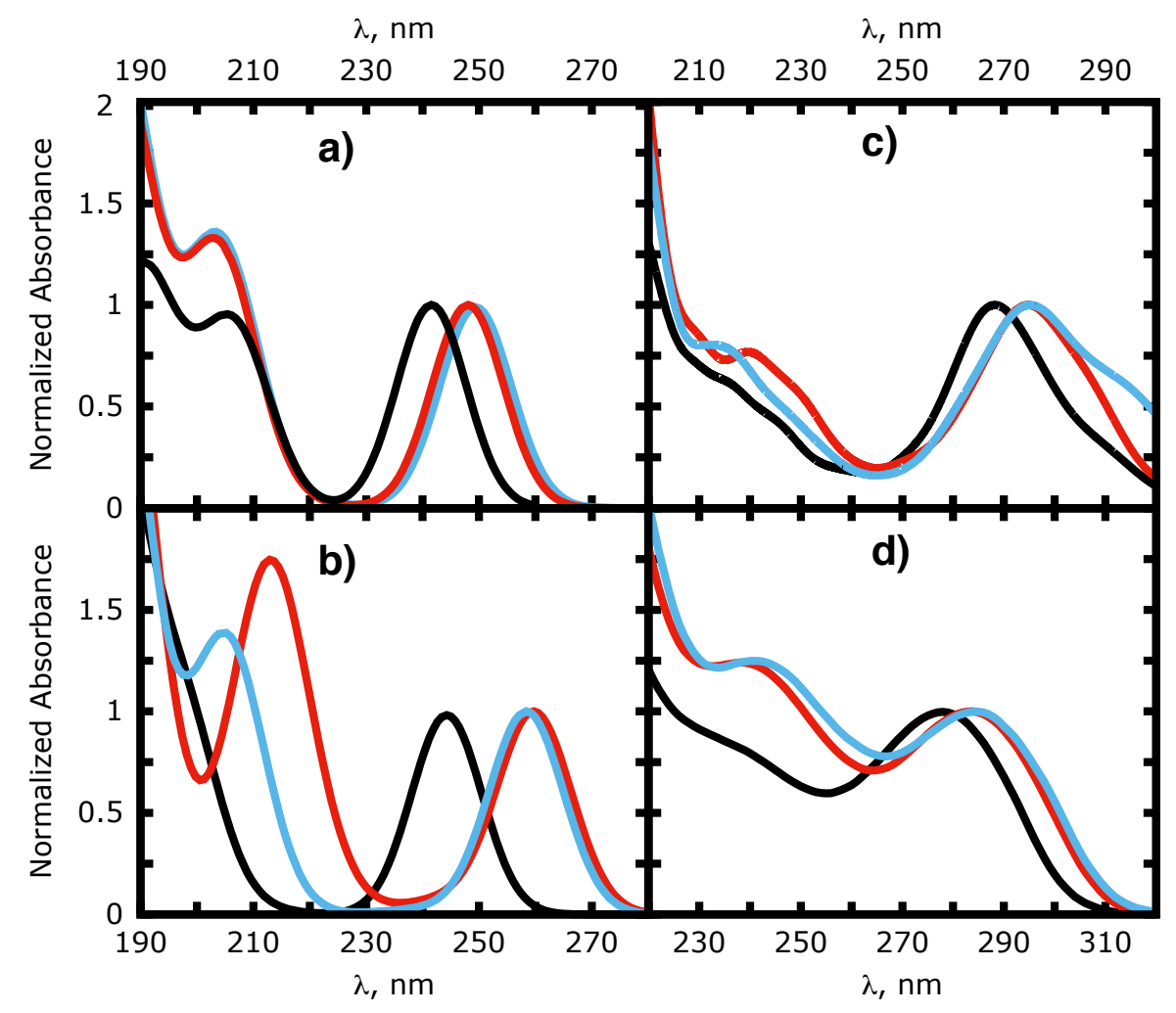

Figure 2. Computed Absorption Spectra of $5 \mathrm{mCd}$ in different solvents THF (blue), ACN (red) and WAT (black) using the static $\mathrm{QM} / \mathrm{PCM}$ a), static $\mathrm{QM} / \mathrm{MM}$ b) and dynamic $\mathrm{QM} / \mathrm{MM} \mathrm{MD}$ c) approaches. Panel d) shows the experimental normalized absorption spectra of $5 \mathrm{mCd}$ in THF, ACN and WAT.

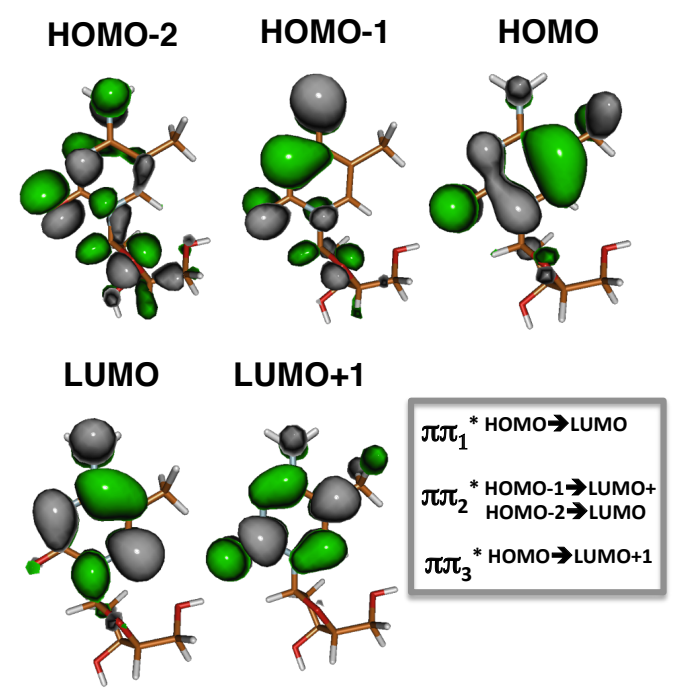

Figure 3. Molecular Orbitals involved in the low lying excited states of $5 \mathrm{mCd}$ in ACN at the CAM-B3LYP/6$31 \mathrm{G}(\mathrm{d})$ level of theory calculated at the optimized ground state minimum. 


\subsection{Emission Spectra}

The experimental fluorescence spectra of $5 \mathrm{mCd}$ in WAT exhibits a maximum at $344 \mathrm{~nm}$. Although its quantum yield is low, $5.9 \times 10^{-4}, 25$ it corresponds to about a $\sim 6$-fold increase with respect to $\mathrm{C}$ nucleobase, $\sim 1 \times 10^{-4} .24,25,82,83$

In order to rationalize the emission properties of $5 \mathrm{mCd}$ from a $\mathrm{QM} / \mathrm{PCM}$ theoretical point of view, the potential energy surface (PES) of the $S_{1}\left(\pi \pi_{1}^{*}\right)$ state has been explored in WAT. Geometry optimization shows that a steep path leads towards a plateau of the PES (energy gradient $\sim 0.001$ a.u.), where the six-membered ring of $5 \mathrm{mCd}$ remains almost planar. A representative point for this region $\left(S_{1}\left(\pi \pi_{1}^{*}\right)^{\text {pla }}\right)$ has been located by optimizing $S_{1}$ imposing the planarity of the pyrimidine ring. If the system is further relaxed, a slight out-of-plane distortion of the ring planarity at the position of the $\mathrm{C}_{6}-\mathrm{N}_{1}$ bond takes place and a shallow absolute minimum $S_{1}\left(\pi \pi_{1}{ }^{*}\right)$ one is found. The energy of $S_{1}\left(\pi \pi_{1}{ }^{*}\right)$ is extremely similar to that of $S_{1}\left(\pi \pi_{1}{ }^{*}\right)^{\text {pla }}$ (their adiabatic energies in WAT are 4.75 and $4.78 \mathrm{eV}$, respectively); the energy difference between the two structures is very small, $\Delta \mathrm{E}=0.04 \mathrm{eV}$, also when using the $6-31+\mathrm{G}(\mathrm{d}, \mathrm{p})$ basis set. Structurally, except for the ring planarity distortion, both minima present similar geometry shifts compared to the $S_{0}$ minimum, with significant lengthening of the $\mathrm{C}_{5}-\mathrm{C}_{6}$ and $\mathrm{C}_{1}-\mathrm{N}_{2}$ bonds (see Figure S1). Nonetheless, their emission energies (see Table 1) are significantly different; it is $282 \mathrm{~nm}(4.39 \mathrm{eV})$ from $\mathrm{S}_{1}\left(\pi \pi_{1}{ }^{*}\right)^{\text {pla }}$ and $316 \mathrm{~nm}(3.92 \mathrm{eV}) \mathrm{S}_{1}\left(\pi \pi_{1}{ }^{*}\right)$, due to the large destabilization of $S_{0}$ caused by the small distortion of the ring planarity. Vertical emission energy from $S_{1}\left(\pi \pi_{1}{ }^{*}\right)$ $316 \mathrm{~nm}$ is closer to the experimental maximum, but since PCM/CAM-B3LYP/6-31G(d) VAEs are significantly blue-shifted, this would lead to a computed Stokes shift $(1.21 \mathrm{eV})$ overestimated with respect to the experimental one $(0.86 \mathrm{eV})$. In fact, the computed Stokes shift obtained considering emission from $S_{1}\left(\pi \pi_{1}^{*}\right)^{\text {pla }}$ is $0.74 \mathrm{eV}$, closer to the experimental one, though underestimated. Considering that the oscillator strength is $20-25 \%$ larger $\left.\mathrm{S}_{1}\left(\pi \pi_{1}\right)^{*}\right)^{\text {pla }}$ than in $\mathrm{S}_{1}\left(\pi \pi_{1}{ }^{*}\right)$ and that the small fluorescence quantum yield suggests a very fast and effective nonradiative decay to $\mathrm{S}_{0}$ (in analogy with what predicted for $\mathrm{C}$ ), ${ }^{30,84-88}$ we propose that emission from $S_{1}\left(\pi \pi_{1}{ }^{*}\right)^{\text {pla }}$ also significantly contributes to the experimental fluorescence spectra, giving account of its broad and structureless shape. Previous studies suggest a dominant role of the planar plateau in the fluorescence of pyrimidine-like nucleobases, in line with the indications of 
Raman Resonance experiments, indicating a small driving force towards distortion of the ring planarity. ${ }^{55,63,89-94} \mathrm{~S}_{1}$ geometry optimization at the CAM-B3LYP/MM level leads directly to a planar $\mathrm{S}_{1}\left(\pi \pi_{1}{ }^{*}\right)^{\text {pla }}$ minimum, which is very similar to that provided by CAM-B3LYP/PCM calculations. The structure of the minimum is similar (differences in the bond lengths are $<0.02 \AA)$, as well as the computed emission energy at $282 \mathrm{~nm}(4.39 \mathrm{eV})$. The QM/MM computed Stokes shifts, which is $0.70 \mathrm{eV}$ in WAT, is also consistent with the experimental one $(0.86 \mathrm{eV})$. As already discussed for the absorption spectrum, it is, important to remind that only inclusion of vibrational effects can allow a full reproduction of the emission maxima. ${ }^{66}$

\section{Emission Solvent Shifts}

Experimental fluorescence maxima are 352 and $351 \mathrm{~nm}$ in $\mathrm{ACN}$ and THF, respectively, observing the same blue-shift going from ACN to WAT (344 nm) as that found in the absorption spectra $\left(\Delta_{\text {WAT } \rightarrow \text { ACN }} 7 \mathrm{~nm} /-0.08 \mathrm{eV}\right)$. The shift found when going from ACN to THF is very small, and we shall not discuss it further, considering the possible source of uncertainty in our calculations of the fluorescence spectrum (lack of vibronic effects, contribution of different regions of the PES to the fluorescence, etc).

The QM/PCM emission energies for both $\mathrm{S}_{1}\left(\pi \pi_{1}{ }^{*}\right)^{\text {pla }}$ in THF and ACN $(291 \mathrm{~nm}(4.26 \mathrm{eV}))$, are very similar, whereas they are lower compared to those found in WAT solution (see Table 1), corresponding to a shift of $\Delta_{\mathrm{WAT} \rightarrow \mathrm{ACN}} 9 \mathrm{~nm} /-0.13 \mathrm{eV}$, which slightly overestimates the experimental value. The QM/MM optimized minima in THF and ACN present emission energy of 3.94 and $3.75 \mathrm{eV}$, respectively, overestimating the experimental shifts, as in the absorption case. In general, small differences $(<0.02 \AA)$ between the different optimized minima in ACN, THF and WAT were found (see Figure S1).

\section{Discussion}

Our experiments have shown that the maximum of $5 \mathrm{mCd}$ lowest energy absorption band (band I in Figure 2) shifts towards the blue when the polarity and, especially, the HB ability of the solvent increases. Independently of the adopted solvation model, our calculations provide the same indication. Due to the strong similarity between $5 \mathrm{mCd}$ and $\mathrm{C}$, this conclusion can be 
extended also to $\mathrm{C}$, whose absorption spectrum has been predicted theoretically to blue-shift in presence of polar solvents. ${ }^{9,}{ }^{10}$ However, these predictions cannot be easily confirmed from an experimental point of view, since the tautomerization equilibrium of $\mathrm{C}$ in the gas phase and in water is different. ${ }^{95}$

On the ground of these results, we shall discuss in the following i) what are the chemical physical effects giving account of solvent effect on the position of band $\mathrm{I}$ of $\mathrm{C}$ and its derivatives and ii) what are the general methodological indications provided by the comparison among the three different solvation models adopted.

\subsection{Explaining solvent shifts in $5 \mathrm{mCd}$ absorption spectrum}

Contrary to what has been observed for $5 \mathrm{mCd}$, the lowest energy absorption band of other pyrimidine bases, as thymine and uracil, undergoes noticeable red shifts $(\sim 0.1-0.2 \mathrm{eV})$ when going from an apolar solvents to WAT. 9, 37, 60, 61, 96-99 Our calculations show that a HB solvent alters the shape of the molecular orbitals involved in the electronic transition responsible of band I. When going from THF to ACN, both the shapes and the relative energies of the HOMO and the LUMO are almost unaltered, being both roughly equally stabilized, in line with the very small solvent shift found. The effect is considerably larger when moving from ACN to WAT, especially for the HOMO (see Figure 4). When $\mathrm{N}_{3}$ acts as $\mathrm{HB}$ acceptor atom, its electron density decreases. This translates into less antibonding character of the orbital in the $\mathrm{N}_{3}-\mathrm{C}_{4}$ and $\mathrm{C}_{2}-\mathrm{O}$ regions, increasing the relative stability of this orbital respect to the LUMO, and thereby the energy of the HOMO $\rightarrow$ LUMO transition. For other pyrimidine bases, as thymine, protonation at $\mathrm{N}_{3}$ avoid the stabilization of the HOMO orbital, and indeed, the HOMO/LUMO gap is decreased. Solvent effect thus does not depend on its polarity but on its $\mathrm{HB}$ ability. From the methodological point of view, this result shows that it is essential to provide an appropriate description of solute-solvent hydrogen bonds. 


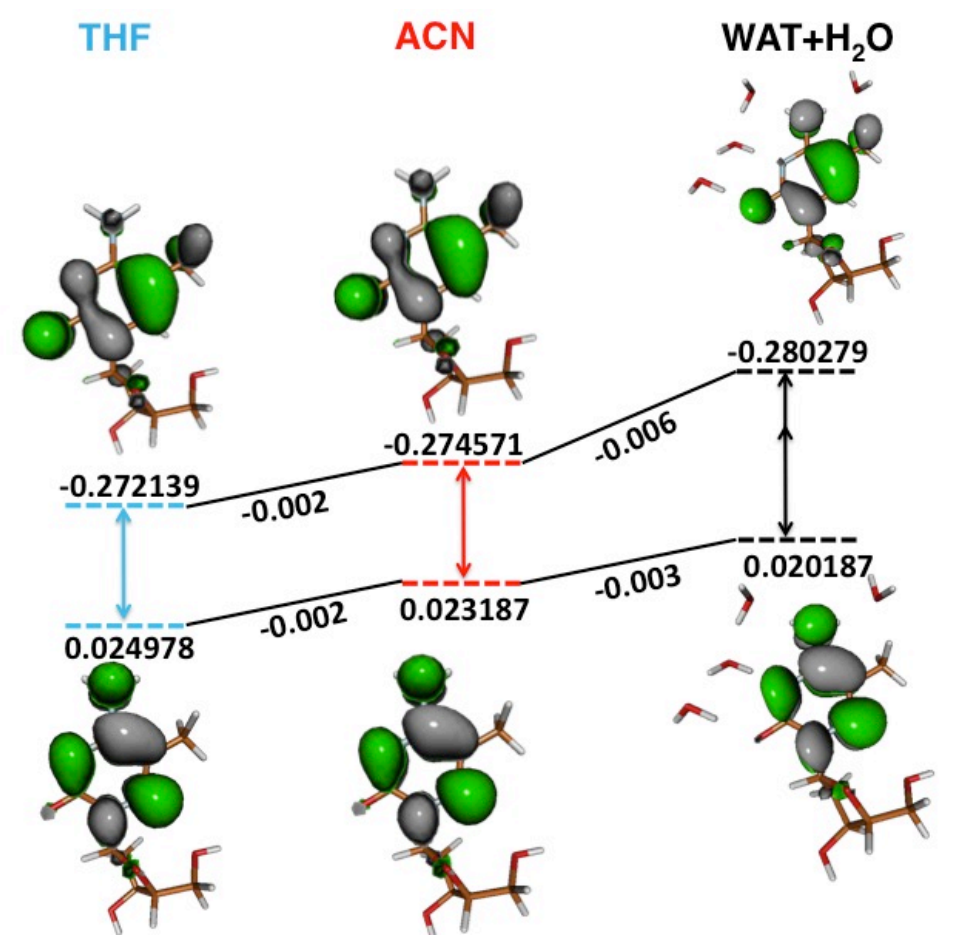

Figure 4. Molecular Orbitals involved in the low energy band transition and their corresponding energies in atomic units in THF, ACN and WAT.

\subsection{A comparison among different solvation models}

The first encouraging indication coming from our study is that, when the underlying QM method is the same, all the adopted solvation methods qualitatively reproduce solvent effect on the position of Band I of $5 \mathrm{mCd}$. On the other hand, both static approaches overestimates vertical transition energies, and the static $\mathrm{QM} / \mathrm{MM}$ approach B) also considerably overestimates $\Delta_{\text {WAT } \rightarrow \text { ACN }}($ see Table 1) for the anti conformer but not for the syn (-0.08 eV see SI). This result is likely due to small inaccuracies in the determination of the $\mathrm{S}_{0}$ minimum for both conformers (see SI), when simulating THF/ACN by a MM force field. These discrepancies are accentuated when comparing QM/PCM and QM/MM excited state minima (see Figure and Table S1). Solutesolvent interactions in water have a strongly directional electrostatic component, which is easier to be modeled by a classical force field, whereas the weak dispersion interactions ruling solvation in ACN and, especially, THF are more challenging for MM force fields, also considering that they have been less thoroughly studied than water.

In general the shape of the experimental spectra is fairly well reproduced by all the approaches, not only for the lowest energy band but also for the entire spectrum up to $200 \mathrm{~nm}$ (see ESI), 
confirming the general reliability of TD-CAM-B3LYP also for higher lying excitations. From a quantitative point of view, TD-CAM-B3LYP/6-31G(d)/PCM estimates are almost uniformly blue-shifted $(0.6 \mathrm{eV})$ with respect to the experimental maxima. As discussed above, the shift decreases by $-0.2 \mathrm{eV}$ extending the basis set, and vibronic effects at $0 \mathrm{~K}$ would account for an extra $-0.2 \mathrm{eV}$ shift. The residual difference is likely due to thermal effects. The importance of including these latter effects is shown by the spectrum computed at the CAM-B3LYP/631G(d)/MM MD level; very remarkably, in this case the position of band I is indeed in quantitative agreement with experiments. Notwithstanding approaches A) and C) shares the same QM level, the spectrum computed by $\mathrm{C}$ ) is red-shifted by ca. $0.6 \mathrm{eV}$. This agreement is partially fortuitous and is due to the use of a MM force field to sample the geometry of $5 \mathrm{mCd}$ (see ESI for a more detailed discussion). The spectrum computed in water by freezing the geometry of $5 \mathrm{mCd}$ to that optimized at the PCM/CAM-B3LYP/6-31G(d) level (model C') is blue-shifted by 20nm with respect to that obtained by model $\mathrm{C}$ and much more similar to that obtained by models $\mathrm{A}$ and $\mathrm{B}$. On the other hand, notwithstanding the effect of thermal fluctuations on the solute geometry is not included, the computed maximum is red-shifted (by $\sim 8 \mathrm{~nm}$ ) with respect to that obtained by static QM/MM approach, showing the importance of an extensive sampling of solvent configurations and of a proper inclusion of the effect of the temperature.

Similar indications are provided by our test AIMD simulation, whose potential is based on CAMB3LYP without resorting to empirical force fields. Notwithstanding the use of a QM method limits the simulation time to $10 \mathrm{ps}$, the predicted maximum of band I falls at $250 \mathrm{~nm}$, i.e. ca $0.20 \mathrm{eV}$ red-shifted with respect the VAE computed in water at the same level of theory statically (see QM/QM MD in Figure 5). Analogously AIMD simulations in GP indicate that the maximum of band I falls at $\sim 262 \mathrm{~nm}$ (see SI), corresponding to a solvent shift of $\sim 12 \mathrm{~nm}$ from gas phase to WAT solution, which is very similar to the THF $\rightarrow$ WAT experimental shift. Inclusion of thermal and dynamical effects by AIMD simulations leads to a $10 \mathrm{~nm}$ red-shift of the maximum of band I, fully confirming our prediction that inclusion of thermal effects (as done at the CAM-B3LYP/6-31G(d)/MM MD level) would lead the computed spectra very close to the experimental ones, when including the vibronic and basis-set effects (as discussed above). Interestingly, CAM-B3LYP/PCM calculations correctly describe the relative intensity of the three main bands, and their dependence on the solvent, accounting for the increase of the band II intensity on going from WAT to ACN/THF. The performance of the CAM-B3LYP/MM MD 
approach is also remarkably good in modeling WAT effects on the intensities and shape of the absorption bands (see Figure 2). However, it is less satisfying for ACN/THF. This is likely due to the inaccuracy of the MM force field employed for those solvents, as already pointed out. A more accurate force field, possibly including polarization effects, may be able to partially mitigate these inaccuracies, its in-depth analysis being out of the scope of the present manuscript. ${ }^{81}$

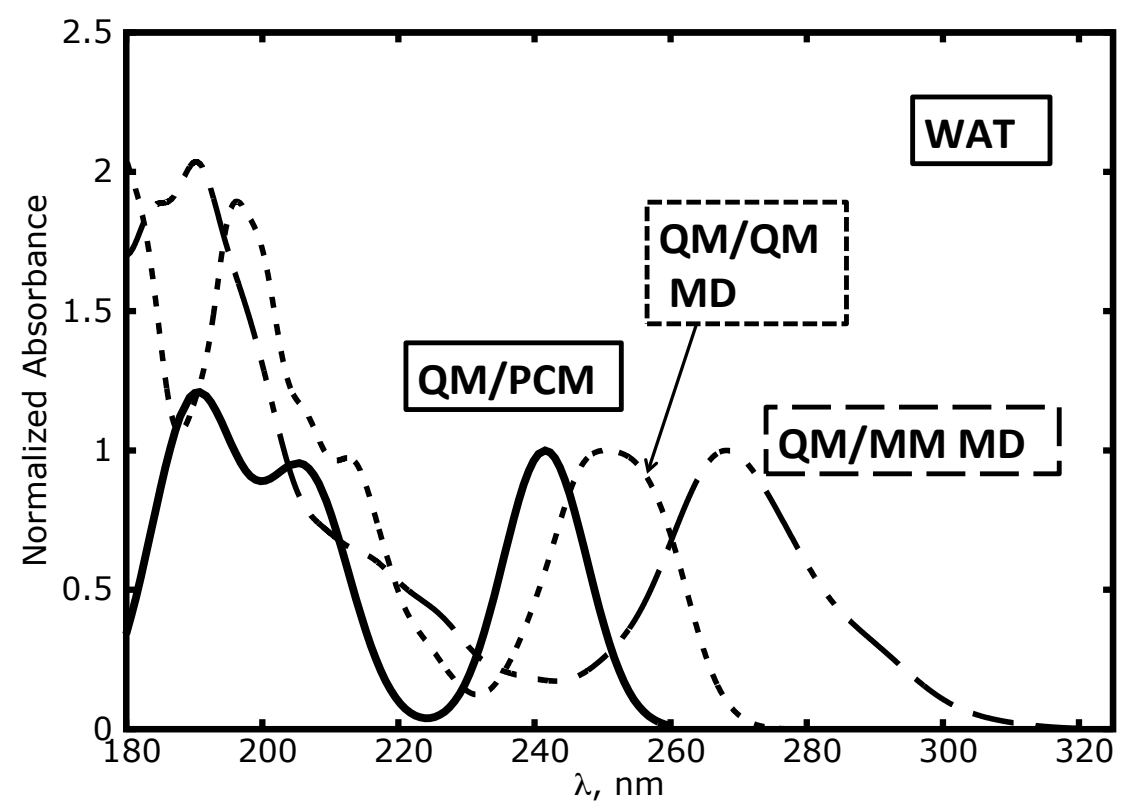

Figure 5. 5mCd absorption spectra in water calculated using the QM/PCM (A), QM/MM MD (C) and QM/QM MD methods.

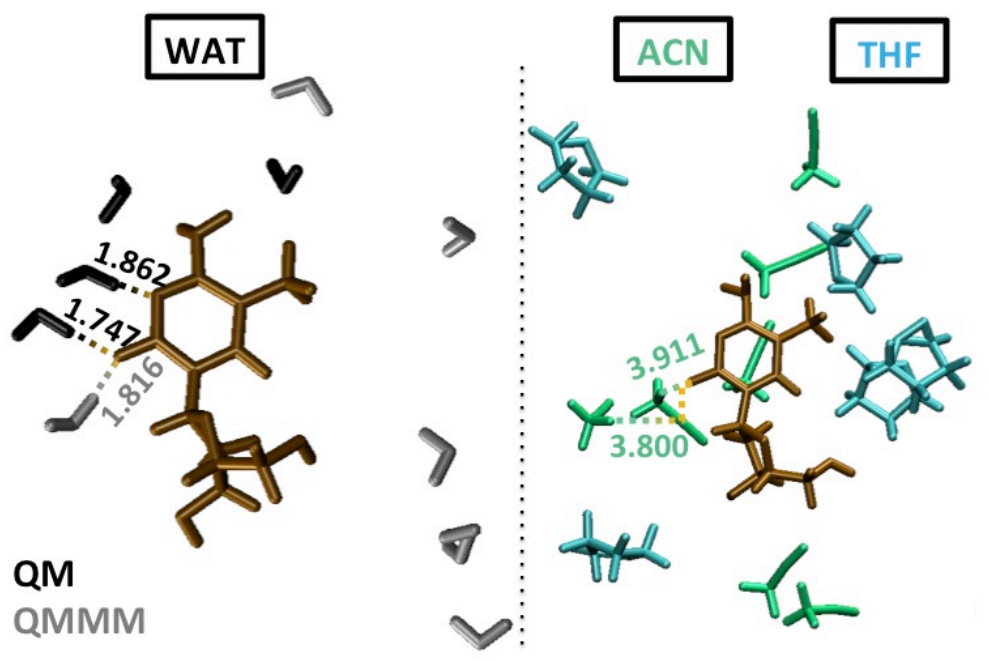

Figure 6. Most probable solvent distribution found during the MD simulations and an example of the QM cluster is also included for comparison. Distances in $\AA$. 
The main disadvantage of QM/ PCM approach is that it is not able to appropriately describe Hbonds. As shown in the SI, it is necessary to include some water molecules of the first solvation shell to correctly predict the $\Delta_{\mathrm{WAT} \rightarrow \mathrm{ACN}}$ shift for $5 \mathrm{mCd}$. It is true that a mixed method as the one we used for water can reproduce the solvent shifts in both absorption and emission spectra, as well as the experimental Stokes shifts. On the other hand, it is also true that this approach suffers from some arbitrariness in deciding the number and the position of the solvent molecules to be included in the QM model. In this respect, the comparison with the results of MD simulations can be very informative. An important advantage of this method is that the presence of some water molecules into the ML of the QM/MM calculations gives a description of the H-bond good enough to match the solvent shifts, what can be crucial for larger systems where the addition of solvent molecules to the QM part is not possible. Furthermore, MD dynamics, besides accounting for thermal effects, can also help on figuring out the most probable distribution of the solvent molecules in the first solvation shell. Figure 6 depicts the most repeated solvent distribution along the MD (WAT, $\mathrm{ACN}$ and THF) MM simulations and for the QM $\left(\mathrm{H}_{2} \mathrm{O}\right)$ calculations, showing that independently on how the $\mathrm{H}_{2} \mathrm{O}$ molecule is treated a strong $\mathrm{H}$-bond (1.747 and $1.816 \AA$ ) is established between them and the Oxygen atom. The dynamical approach outperforms the static one in predicting a non-zero absorption in the region between band I and II. Giving account of the structural flexibility allows indeed the dark excited states falling between $\pi \pi_{1}$ and $\pi \pi_{2}$ transitions to acquire some oscillator strength. The computed intensity at this region is, in any case, lower than the experimental one. In this respect, CAM-B3LYP/MM MD calculations, besides correctly predicting the band maxima, gives partially account of the broadening effect due to the fluctuations of the geometry of the solute and of the solute-solvent interaction. On the other hand, the predicted absorption at $\sim 240 \mathrm{~nm}$ is still significantly underestimated with respect to the experimental spectra. Inclusion of Quantum vibronic effects, resulting in a further increase of the computed band-width, would partially recover this discrepancy, in line with the promising results recently obtained on oligothiophenes by using mixed Quantum/Classical approaches. ${ }^{100-104}$ These approaches (whose application is well beyond the scope of the present work) are based on the separation of high-frequency 'molecular' vibrational modes, which are treated at a fully Quantum vibronic level, and low-frequency 'environmental' (large amplitude motion of the solute, solvent fluctuations) modes, whose effect is included by using classical MD simulations. 


\section{Conclusions.}

In this study we report a thorough analysis of the spectroscopic properties of 5-methylcytidine in solvents of different polarity and hydrogen bonding properties (tetrahydrofuran, acetonitrile and water), comparing the experimental absorption and emission spectra with those computed adopting different computational approaches, based on TD-CAMB3LYP functional. For the absorption we have adopted i) a fully QM, static, approach including solvent effect by a continuum model and, in water, a small number of water molecules of the first solvation shell ii) a similar QM/MM approach where solvent effects are mimicked including a large number of solvent molecules, treated at the MM level and iii) a dynamic QM/MM model, simulating the absorption spectrum by $\mathrm{QM} / \mathrm{MM}$ single point calculations on a large number of structures issuing from MM MD simulations. Only the first two approaches have been used to simulate the fluorescence spectra. On the balance, all the adopted approaches reproduce the significant blueshift of the lowest energy absorption band in water, and provide a fairly accurate prediction of the absorption spectrum over $200 \mathrm{~nm}$ (also considering the three higher energy bands) and of the Stokes shift, the dynamical QM/MM approach nicely matching the experimental absorption maxima and spectral shapes, thus confirming the general reliability of TD-CAMB3LYP and the accuracy of this treatment. The blue-shift of the lowest energy band in water is explained by the effect of solute-solvent hydrogen bonds on the frontier orbital of 5-methylcytidine, highlighting the importance of explicitly including these interactions in the adopted computational model. The comparison among the adopted solvation models indicates that the adoption of mixed classical/quantum approaches could constitute the last step for a completely satisfactory comparison between experimental and computational spectra.

\section{Associated Content}

Additional computational details and results together with further analysis of the syn/anti conformers, the FC region and the dynamic QM/MM approach. This information is available free of charge via the Internet at http://pubs.acs.org/. 


\section{Acknowledgements}

R. I. thanks CNR, Progetto Bilaterale CNR/CNRS PICS 2015 and the French Agency Research Grant ANR-12-BS08-0001-01 for financial support. L. M.-F. acknowledges the LR. Campania num 5/2002- Annualità 2007.

M.G. acknowledges support by the European Research Council Advanced Grant STRA- TUS (ERC-2011-AdG No. 291198) and of the French Agence National de la Recherche (FEMTO2DNA, ANR-15-CE29-0010). J.S-M. acknowledges Project No. CTQ2014-58624-P of the

Spanish MINECO (Ministerio de Economia y Competitividad) and Project No. GV2015-057 of the Generalitat Valenciana.

A. B. acknowledges Justina Jovaišaite for her help in the steady-state spectroscopic experiments and the support of the international scientific cooperation project PICS n 6827.

\section{References}

1. Gustavsson, T.; Improta, R.; Markovitsi, D., J. Phys. Chem. Lett. 2010, 1, 2025-2030.

2. Improta, R.; Barone, V., Excited States Behavior of Nucleobases in Solution: Insights from Computational Studies. In Photoinduced Phenomena in Nucleic Acids I, Barbatti, M.; Borin, A. C.; Ullrich, S., Eds. Springer International Publishing: 2015; 355, 329-357.

3. Giussani, A.; Segarra-Martí, J.; Roca-Sanjuán, D.; Merchán, M., Excitation of Nucleobases from a Computational Perspective I: Reaction Paths. In Photoinduced Phenomena in Nucleic Acids I: Nucleobases in the Gas Phase and in Solvents, Barbatti, M.; Borin, C. A.; Ullrich, S., Eds. Springer International Publishing: Cham, 2015; 355, 57-97.

4. Mai, S.; Richter, M.; Marquetand, P.; González, L., Excitation of Nucleobases from a Computational Perspective II: Dynamics. In Photoinduced Phenomena in Nucleic Acids I: Nucleobases in the Gas Phase and in Solvents, Barbatti, M.; Borin, C. A.; Ullrich, S., Eds. Springer International Publishing: Cham, 2015; 355, 99-153.

5. Barbatti, M.; Borin, A. C.; Ullrich, S., Photoinduced Processes in Nucleic Acids. In Photoinduced Phenomena in Nucleic Acids I: Nucleobases in the Gas Phase and in Solvents, Barbatti, M.; Borin, C. A.; Ullrich, S., Eds. Springer International Publishing: Cham, 2015; 1-32. 6. Improta, R.; Santoro, F.; Blancafort, L., Chem. Rev. 2016, 116, 3540-3593.

7. Middleton, C. T.; de La Harpe, K.; Su, C.; Law, Y. K.; Crespo-Hernández, C. E.; Kohler, B., Annu. Rev. Phys. Chem. 2009, 60, 217-239.

8. Crespo-Hernández, C. E.; Cohen, B.; Hare, P. M.; Kohler, B., Chem. Rev. 2004, 104, 1977-2020. 
9. Kistler, K. A.; Matsika, S., J. Phys. Chem. A. 2009, 113, 12396-12403.

10. Blancafort, L.; Migani, A., J. Photochem. and Photobiol. A: Chem. 2007, 190, 283-289.

11. Ko, M.; Huang, Y.; Jankowska, A. M.; Pape, U. J.; Tahiliani, M.; Bandukwala, H. S.; An, J.; Lamperti, E. D.; Koh, K. P.; Ganetzky, R.; Liu, X. S.; Aravind, L.; Agarwal, S.; Maciejewski, J. P.; Rao, A., Nature 2010, 468, 839-843.

12. Ogino, M.; Taya, Y.; Fujimoto, K., Chem. Commun. 2008, 5996-5998.

13. Motorin, Y.; Lyko, F.; Helm, M., Nucleic Acids Res. 2010, 38, 1415-1430.

14. Booth, M. J.; Branco, M. R.; Ficz, G.; Oxley, D.; Krueger, F.; Reik, W.; Balasubramanian, S., Science 2012, 336, 934-937.

15. Krebs, J. E.; Goldstein, E. S.; Kilpatrick, S. T., Lewin's Genes X. Jones \& Barlett Publishers: 2011.

16. Momparler, R. L.; Bovenzi, V., J. Cell. Physio. 2000, 183, 145-154.

17. Ehrlich, M.; Gama-Sosa, M. A.; Huang, L.-H.; Midgett, R. M.; Kuo, K. C.; McCune, R. A.; Gehrke, C., Nucleic Acids Res. 1982, 10, 2709-2721.

18. Baylin, S. B., Nat. Clin. Prac. Oncol. 2005, 2, S4-S11.

19. Pfeifer, G. P.; You, Y.-H.; Besaratinia, A., Mutat. Res. 2005, 571, 19-31.

20. Duncan, B. K.; Miller, J. H., Nature 1980, 287, 560-561.

21. Esposito, L.; Banyasz, A.; Douki, T.; Perron, M.; Markovitsi, D.; Improta, R., J. Am. Chem. Soc. 2014, 136, 10838-10841.

22. Barna, T.; Malinowski, J.; Holton, P.; Ruchirawat, M.; Becker, F. F.; Lapeyre, J. N., Nucleic Acids Res. 1988, 16, 3327-3340.

23. Tommasi, S.; Denissenko, M. F.; Pfeifer, G. P., Cancer Res. 1997, 57, 4727-4730.

24. Sharonov, A.; Gustavsson, T.; Marguet, S.; Markovitsi, D., Photochem. Photobiol. Sci. 2003, 2, 362-364.

25. Ma, C.; Cheng, C. C.-W.; Chan, C. T.-L.; Chan, R. C.-T.; Kwok, W.-M., Phys. Chem. Chem. Phys. 2015, 17, 19045-19057.

26. Malone, R. J.; Miller, A. M.; Kohler, B., Photochem. Photobiol. 2003, 77, 1751-1097.

27. Blaser, S.; Trachsel, M. A.; Lobsiger, S.; Wiedmer, T.; Frey, H.-M.; Leutwyler, S., J. Phys. Chem. Lett. 2016, 752-757.

28. Li, Q.; Blancafort, L., Photochem. Photobiol. Sci. 2013, 12, 1401-1408.

29. Zgierski, M. Z.; Patchkovskii, S.; Lim, E. C., J. Chem. Phys. 2005, 123, 081101-081104.

30. Blancafort, L.; Cohen, B.; Hare, P. M.; Kohler, B.; Robb, M. A., J. Phys. Chem. A 2005, 109, 4431-4436.

31. Nakayama, A.; Yamazaki, S.; Taketsugu, T., J. Phys. Chem. A 2014, 118, 9429-9437.

32. Ho, J.-W.; Yen, H.-C.; Shi, H.-Q.; Cheng, L.-H.; Weng, C.-N.; Chou, W.-K.; Chiu, C.C.; Cheng, P.-Y., Angew. Chem. Int. Ed. 2015, 54, 14772-14776.

33. Kistler, K. A.; Matsika, S., The Journal of Physical Chemistry A 2007, 111, 2650-2661.

34. Kistler, K. A.; Matsika, S., The Journal of Physical Chemistry A 2007, 111, 8708-8716.

35. Lobsiger, S.; Etinski, M.; Blaser, S.; Frey, H.-M.; Marian, C.; Leutwyler, S., J. Chem. Phys. 2015, 143, 234301/1-234301/12.

36. Trachsel, M. A.; Lobsiger, S.; Leutwyler, S., J. Phys. Chem. B 2012, 116, 11081-11091.

37. Improta, R.; Barone, V., J. Am. Chem. Soc. 2004, 126, 14320-14321.

38. Ludwig, V.; Amaral, M. S. d.; da Costa, Z. M.; Borin, A. C.; Canuto, S.; Serrano-Andrés, L., Chem. Phys. Lett. 2008, 463, 201-205.

39. Reichardt, C.; Welton, T., Solvents and Solvent Effects in Organic Chemistry. Wiley: London, 2010. 
40. Ungnade, H. E., J. Am. Chem. Soc. 1952, 75, 432-434.

41. Prabhu, N.; Sharp, K., Chem. Rev. 2006, 106, 1616-1623.

42. Whitehead, M.; Turega, S.; Stephenson, A.; Hunter, C. A.; Ward, M. D., Chem. Sci. 2013, 4, 2744-2751.

43. Grubbs, R. B., Nat Mater 2007, 6, 553-555.

44. Havenith, M., Angew. Chem. Int. Ed. 2016, 55, 1218-1219.

45. Monard, G.; Rivail, J.-L., Solvent Effects in Quantum Chemistry. In Handbook of Computational Chemistry, Leszczynski, J., Ed. Springer Netherlands: 2012; 561-571.

46. Improta, R., UV-visible absorption and emission energies in condensed phase by PCMTD-DFT methods. Wiley: Chichester, 2011.

47. Mennucci, B.; Cammi, R., Continuum solvation models in chemical physics: from theory to applications. Wiley: New York, 2007.

48. Miertuš, S.; Scrocco, E.; Tomasi, J., Chem. Phys. 1981, 55, 117-129.

49. Tomasi, J.; Mennucci, B.; Cammi, R., Chem. Rev. 2005, 105, 2999-3094.

50. Tomasi, J.; Persico, M., Chem. Rev. 1994, 94, 2027-2094.

51. Gao, J., Acc. Chem. Res. 1996, 29, 298-305.

52. Orozco, M.; Luque, F. J., Chem. Rev. 2001, 101, 203-204.

53. Orozco, M.; Luque, F. J., Chem. Rev. 2000, 100, 4187-4226.

54. Cramer, C. J.; Truhlar, D. G., Chem. Rev. 1999, 99, 2161-2200.

55. Santoro, F.; Barone, V.; Gustavsson, T.; Improta, R., J. Am. Chem. Soc. 2006, 128, 16312-16322.

56. Gustavsson, T.; Improta, R.; Banyasz, A.; Vaya, I.; Markovitsi, D., J. Photochem. and Photobiol. A: Chem. 2012, 234, 37-43.

57. Bányász, Á.; Karpati, S.; Mercier, Y.; Reguero, M.; Gustavsson, T.; Markovitsi, D.; Improta, R., J. Phys. Chem. B 2010, 114, 12708-12719.

58. Xu, Z.; Matsika, S., J. Phys. Chem. A 2006, 110, 12035-12043.

59. Bistafa, C.; Canuto, S., Theor. Chem. Acc. 2012, 132, 1-10.

60. Gustavsson, T.; Sarkar, N.; Lazzarotto, E.; Markovitsi, D.; Improta, R., Chem. Phys. Lett. 2006, 429, 551-557.

61. Gustavsson, T.; Bányász, Á.; Lazzarotto, E.; Markovitsi, D.; Scalmani, G.; Frisch, M. J.; Barone, V.; Improta, R., J. Am. Chem. Soc. 2006, 128, 607-619.

62. Santoro, F., FC classes, a Fortran 77 code, development version.: The standard version of the code can be downloaded at http://www.pi.iccom.cnr.it/fcclasses, last accessed March 52015.

63. Avila Ferrer, F. J.; Santoro, F.; Improta, R., Comput. Theor. Chem. 2014, 1040-1041, 186-194.

64. Petrone, A.; Cerezo, J.; Ferrer, F. J. A.; Donati, G.; Improta, R.; Rega, N.; Santoro, F., J. Phys. Chem. A 2015, 119, 5426-5438.

65. Ferrer, F. J. A.; Improta, R.; Santoro, F.; Barone, V., Phys. Chem. Chem. Phys. 2011, 13, 17007-17012.

66. Avila Ferrer, F. J.; Cerezo, J.; Stendardo, E.; Improta, R.; Santoro, F., J. Chem. Theor. Comput. 2013, 9, 2072-2082.

67. Altoè, P.; Stenta, M.; Bottoni, A.; Garavelli, M., Theor. Chem. Acc. 2007, 118, 219-240.

68. Yanai, T.; Tew, D. P.; Handy, N. C., Chem. Phys. Lett. 2004, 393, 51-57.

69. Hariharan, P. C.; Pople, J. A., Theor. Chim. Acta 1973, 28, $213-222$.

70. Mennucci, B.; Tomasi, J.; Cammi, R.; Cheeseman, J. R.; Frisch, M. J.; Devlin, F. J.; Gabriel, S.; Stephens, P. J., J. Phys. Chem. A 2002, 106, 6102-6113. 
71. Schlegel, H. B.; Millam, J. M.; Iyengar, S. S.; Voth, G. A.; Scuseria, G. E.; Daniels, A. D.; Frisch, M. J., J. Chem. Phys. 2001, 114, 9758-9763.

72. Frisch, M. J., et al Gaussian 09, Revision A.1, in, Gaussian, Inc., Wallingford CT 2009.

73. Case, D. A.; Darden, T. A.; Cheatham, T. E.; Simmerling, C. L.; Wang, J.; Duke, R. E.; Luo, R.; Walker, R. C.; Zhang, W.; Merz, K. M. Amber 11; University of California: 2010.

74. Jorgensen, W. L.; Chandrasekhar, J.; Madura, J. D.; Impey, R. W.; Klein, M. L., J. Chem. Phys. 1983, 79, 926-935.

75. Wang, J.; Wolf, R. M.; Caldwell, J. W.; Case, D. A., J. Comput. Chem. 2004, 25, 11571174.

76. Altavilla, S. F.; Segarra-Martí, J.; Nenov, A.; Conti, I.; Rivalta, I.; Garavelli, M., Frontiers in Chemistry 2015, 3.

77. Case, D. A.; Darden, T. A.; Cheatham Iii, T. E.; Simmerling, C. L.; Wang, J.; Duke, R. E.; Luo, R.; Merz, K. M.; Wang, B.; Pearlman, D. A., University of California, San Francisco 2004, 5, 39 .

78. Chung, L. W.; Sameera, W. M. C.; Ramozzi, R.; Page, A. J.; Hatanaka, M.; Petrova, G. P.; Harris, T. V.; Li, X.; Ke, Z.; Liu, F.; Li, H.-B.; Ding, L.; Morokuma, K., Chem. Rev. 2015, 115, 5678-5796.

79. Onidas, D.; Markovitsi, D.; Marguet, S.; Sharonov, A.; Gustavsson, T., J. Phys. Chem. B 2002, 106, 11367-11374.

80. Velapoldi, R. A.; Mielenz, K. D., A fluorescence standard reference material: quinine sulfate dihydrate; U. S. Government Printing Office: Washington, D.C., 1980.

81. Li, Q.; Mennucci, B.; Robb, M. A.; Blancafort, L.; Curutchet, C., J. Chem. Theor. Comput. 2015, 11, 1674-1682.

82. Daniels, M.; Hauswirth, W., Science 1971, 171, 675-677.

83. Pollum, M.; Martínez-Fernández, L.; Crespo-Hernández, C. E., Photochemistry of Nucleic Acid Bases and Their Thio- and Aza-Analogues in Solution. In Photoinduced Phenomena in Nucleic Acids I: Nucleobases in the Gas Phase and in Solvents, Barbatti, M.; Borin, C. A.; Ullrich, S., Eds. Springer International Publishing: Cham, 2015; 355, 245-327.

84. Kistler, K. A.; Matsika, S., J. Chem. Phys. 2008, 128, 215102/1-215102/14.

85. Barbatti, M.; Aquino, A. J.; Szymczak, J. J.; Nachtigallová, D.; Hobza, P.; Lischka, H., Proc. Natl. Acad. Sci. USA 2010, 107, 21453-21458.

86. Richter, M.; Marquetand, P.; González-Vázquez, J. s.; Sola, I.; González, L., J. Phys. Chem. Lett. 2012, 3, 3090-3095.

87. Ismail, N.; Blancafort, L.; Olivucci, M.; Kohler, B.; Robb, M. A., J. Am. Chem. Soc. 2002, 124, 6818-6819.

88. Merchán, M.; Serrano-Andrés, L., J. Am. Chem. Soc. 2003, 125, 8108-8109.

89. Billinghurst, B. E.; Loppnow, G. R., J. Phys. Chem. A 2006, 110, 2353-2359.

90. Billinghurst, B. E.; Yeung, R.; Loppnow, G. R., J. Phys. Chem. A 2006, 110, 6185-6191.

91. Fodor, S. P. A.; Rava, R. P.; Hays, T. R.; Spiro, T. G., J. Am. Chem. Soc. 1985, 107, 1520-1529.

92. Peticolas, W. L.; Rush, T., J. Comput. Chem. 1995, 16, 1261-1270.

93. Merchán, M.; González-Luque, R.; Climent, T.; Serrano-Andrés, L.; Rodríguez, E.; Reguero, M.; Peláez, D., J. Phys. Chem. B 2006, 110, 26471-26476.

94. Picconi, D.; Barone, V.; Lami, A.; Santoro, F.; Improta, R., ChemPhysChem 2011, 12, 1957-1968. 
95. Bazso, G.; Tarczay, G.; Fogarasi, G.; Szalay, P. G., Phys. Chem. Chem. Phys. 2011, 13, 6799-6807.

96. Etinski, M.; Marian, C. M., Phys. Chem. Chem. Phys. 2010, 12, 4915-4923.

97. Zazza, C.; Amadei, A.; Sanna, N.; Grandi, A.; Chillemi, G.; Di Nola, A.; D'Abramo, M.; Aschi, M., Phys. Chem. Chem. Phys. 2006, 8, 1385-1393.

98. Ludwig, V.; Coutinho, K.; Canuto, S., Phys. Chem.Chem. Phys. 2007, 9, 4907-4912.

99. Clark, L. B.; Tinoco, I., J. Am. Chem. Soc. 1965, 87, 11-15.

100. Improta, R.; Avila Ferrer, F. J.; Stendardo, E.; Santoro, F., ChemPhysChem 2014, 2014 , 3320-3333.

101. Stendardo, E.; Avila Ferrer, F.; Santoro, F.; Improta, R., Theor. Chem. Acc. 2016, 135, 117.

102. Cerezo, J.; Avila Ferrer, F. J.; Prampolini, G.; Santoro, F., J. Chem. Theor. Comput. 2015, $11,5810-5825$.

103. Zaleśny, R.; Murugan, N. A.; Gel'mukhanov, F.; Rinkevicius, Z.; Ośmiałowski, B.; Bartkowiak, W.; Ågren, H., J. Phys. Chem. A 2015, 119, 5145-5152.

104. Sjoqvist, J.; Gonzalez-Cano, R. C.; Lopez Navarrete, J. T.; Casado, J.; Ruiz Delgado, M. C.; Linares, M.; Norman, P., Phys. Chem. Chem. Phys. 2014, 16, 24841-24852. 